\title{
Oleanane Triterpenoids from Cedrela montana (Meliaceae)
}

Leonardo Castellanos ${ }^{\mathrm{a}}$, Rosabel S. de Correa ${ }^{\mathrm{a}}$, Eduardo Martínez $^{\mathrm{a}}$, and José S. Calderon ${ }^{b, *}$

a Departamento de Química, Universidad Nacional de Colombia, Ciudad Universitaria, Santa Fé de Bogotá Colombia

b Instituto de Química, Universidad Nacional Autónoma de México, Circuito Exterior, Ciudad Universitaria, Coyoacán 04510. México D. F. Fax: (5255) 56162203.

E-mail: uscalder@correo.unam.mx

* Autor for correspondence and reprints requests

Z. Naturforsch. 57c, 575-578 (2002); received February 8/March 22, 2002

Cedrela montana, Meliaceae, Oleanan-28,13 $\beta$-olides

Two new oleanane-type triterpenes, characterized as 3-oxo-11 $\alpha, 12 \alpha$-epoxy-oleanan-28,13 $\beta$ olide and 3-oxo-olean-11-en-28,13 $\beta$-olide, were isolated from the fruits and seeds of Cedrela montana (Meliaceae). In addition, the known compounds oleanonic acid, a mixture of $\beta$-sitosterol and stigmasterol, and the limonoid photogedunin were also isolated. The structures of the new compounds were established by spectroscopic methods, including 2D NMR.

\section{Introduction}

The family Meliaceae, comprising about 50 genera and 1400 species, forms a large botanical family of mostly pantropical distribution. The trees are valued for their quality wood and resistance to the attack of several pest of insects (Banerji and Nigam, 1984). Cedrela montana Turczaninov (Meliaceae) belongs to the Meliaceae plant family highly prized in traditional medicine for their antitumor activity (Champagne et al., 1992). No previous studies on the phytochemistry and biological activity of this species have been reported. We report here on the isolation and structural characterization of two new olean-28,13 $\beta$-olides and the known $\beta$-sitosterol, stigmasterol, oleanonic acid and the limonoid photogedunin. Although oleanane triterpenoids are widely distributed, olean$28,13 \beta$-olides do not commonly occur in nature, to our knowledge only sixteen have been isolated from nature (Ahmad and Atha-ur-Rahman 1994) and three have been synthesized. (Barton and Holness, 1952; Kitagawa et al., 1968, Majumder and Bagchi, 1983). Although the oleanonic acid triterpenoid has been isolated recently from $\mathrm{Ce}$ drela odorata (Campos et al., 1991), this is the first report of oleanan-28,13 $\beta$-olides from Cedrela species.

\section{Results and Discussion}

Fruits and seeds of C. montana were extracted with petroleum ether and dichloromethane followed in each case by CC over silica-gel (see Experimental). This procedure gave two new triterpene lactones named 3-oxo-11 $\alpha, 12 \alpha$-epoxy-olean$28,13 \beta$-olide (1) and 3-oxo-olean-11-en,28,13 $\beta$ olide (2). In addition the known $\beta$-sitosterol, stigmasterol, oleanonic acid (3) (Campos et al., 1991) and photogedunin (4) (Céspedes et al., 1999) were isolated. Identification of the known compounds was based on the comparison of their spectroscopic $\left({ }^{1} \mathrm{H},{ }^{13} \mathrm{C}\right.$ and EIMS) and physical (m.p.) data reported in the literature.

Compound 1 was obtained as colorless crystals, m.p. $281{ }^{\circ} \mathrm{C}$. Its molecular formula $\mathrm{C}_{30} \mathrm{H}_{44} \mathrm{O}_{4}$ was deduced from the EIMS spectrum $\left(\mathrm{M}^{+}, m / z\right.$ 468) and by quantification of the number of methyl, methylene, methine and quaternary carbon atoms revealed in the ${ }^{13} \mathrm{C}$ NMR and DEPT spectra (Table I). The IR spectrum of $\mathbf{1}$ displayed bands at 1770 and $873 \mathrm{~cm}^{-1}$ characteristic of an epoxy- $\gamma$ lactone moiety (Hui and Li, 1976; Kitagawa et al., 1972 ; Majumder and Bagchi, 1983). A further band at $1708 \mathrm{~cm}^{-1}$ suggested the presence of a sixmembered ring ketone, which was also supported by a resonance at $\delta 216.2$ (s) for a carbonyl carbon in the ${ }^{13} \mathrm{C}$ NMR spectrum of $\mathbf{1}$ (Seo et al., 1975). The ${ }^{1} \mathrm{H}$ NMR spectrum of $\mathbf{1}$ showed signals for 

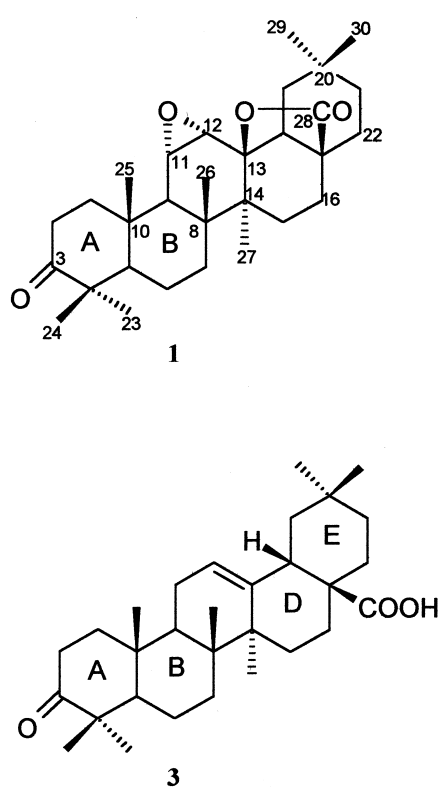

seven tertiary methyl groups at $\delta 0.93,1.00,1.11$ $(6 \mathrm{H}), 1.19,1.06$, and $1.10 \mathrm{ppm}$ and one, two proton signal at $\delta 3.07(\mathrm{br}, \mathrm{s})$ which agreed with those reported for oleanane triterpenoids possessing an $11 \alpha, 12 \alpha$ epoxy group (Hui and Li, 1976; Kitagawa et al., 1968; Majumder and Bagchi, 1983). Furthermore, the ${ }^{13} \mathrm{C}$ NMR spectrum exhibited resonances at $\delta 52.5$ (d), 57.0 (d), 87.3 (s) and 179.2 (s) which were assigned to $\mathrm{C}-11, \mathrm{C}-12, \mathrm{C}-13$, and C-28, respectively, and agreed closely with those reported for $11 \alpha, 12 \alpha$-epoxy-olean-28,13 $\beta$-olides (Ikuta and Morikawa, 1992; Iwamoto et al., 1985). Moreover, the resonances at $\delta 52.5$ (d) and 57.0 (d) attributed to the epoxide group, correlated with the signal at $\delta 3.07(\mathrm{br}, \mathrm{s})$ in the HETCOR spectrum. In addition, the ${ }^{13} \mathrm{C}$ NMR and DEPT spectra of $\mathbf{1}$ revealed the presence of seven methyls, five methines, nine methylenes and nine quaternary carbons which provided further evidence for a pentacyclic triterpene skeleton. On the basis of the above spectra evidence the structure of compound $\mathbf{1}$ was established as 3-oxo-11 $\alpha, 12 \alpha$ epoxy-oleanan-28,13ß-olide.

Compound 2, was isolated as a gummy solid. Its molecular formula $\mathrm{C}_{30} \mathrm{H}_{44}$ O3 determined by EIMS $\left(\mathrm{M}^{+}, m / z 452\right)$ was confirmed by ${ }^{13} \mathrm{C}$ NMR and DEPT analysis. The IR spectrum of 2 displayed absorption bands at 1765,1705 and 1640 $\mathrm{cm}^{-1}$ assigned to a $\gamma$-lactone, a six-membered ring ketone and a double bond groups respectively. The ${ }^{1} \mathrm{H}$ NMR spectrum of 2 (Table I) exhibited signals for seven tertiary methyl groups, characteristic for oleanan-28,13ß-olides (Hui and Li, 1976; Ikuta and Morikawa, 1992).Further signals were observed at $\delta 6.04(\mathrm{~d}, \mathrm{~d}, J=10.6$ and $1.3 \mathrm{~Hz})$ and $5.46(\mathrm{~d}, \mathrm{~d}, J=10.2$ and $3.1 \mathrm{~Hz})$, indicating the presence of a $-\mathrm{CH}-\mathrm{CH}=\mathrm{CH}$ group in the structure of 2. The chemical shifts and coupling constants agree closely with those reported for $3 \beta$-hydroxyolean-11-en-28,13ß-olide isolated from Hyptis albida (Pereda-Miranda and Delgado, 1990). Furthermore, the ${ }^{13} \mathrm{C}$ NMR spectrum of 2 displayed resonances at $\delta 135.2(\mathrm{~d}), 127.4(\mathrm{~d}), 89.6(\mathrm{~s})$ and 180.0 for C-11, C-12, C-13 and C-28 respectively which confirmed the olean-11-en,28,13 $\beta$-olide structure (Pereda-Miranda and Delgado, 1990). All the above mentioned spectral data established the structure of compound 2 as 3-oxo-olean-11en, $28,13 \beta$-olide.

\section{Experimental}

\section{General}

Melting points, uncorrected. ${ }^{1} \mathrm{H}-\mathrm{NMR}$ : TMS as int. standard. CC: silica-gel 60, 70-230 mesh. TLC: precoated silica-gel $60 \mathrm{~F}_{254}$ (Merck, $1.0 \mathrm{~mm}$ ). Spots were visualized by UV $(254 \mathrm{~nm})$ and $10 \%$ $\mathrm{CeSO}_{4}-\mathrm{H}_{2} \mathrm{SO}_{4}$ reagent followed by heating. 
Table I. ${ }^{1} \mathrm{H}$ and ${ }^{13} \mathrm{C}$ NMR spectral data for $\mathbf{1}$ and $\mathbf{2}\left(\mathrm{CDCl}_{3}\right.$, TMS as int. standard) $)^{\mathrm{a}, \mathrm{b}}$.

\begin{tabular}{|c|c|c|c|c|}
\hline Position & $\begin{array}{l}\text { Compound } 1 \\
\delta_{\mathrm{H}}\end{array}$ & $\delta_{\mathrm{C}}$ & $\underset{\delta_{\mathrm{H}}}{\text { Compound } 2} \mathbf{2}$ & $\delta_{\mathrm{C}}$ \\
\hline 1 & & $38.7 \mathrm{t}$ & & $39.0 \mathrm{t}$ \\
\hline $2 \mathrm{ax}$ & $2.67 \mathrm{ddd}(16.1,12.0,6.9)$ & $33.8 \mathrm{t}$ & $2.65 \mathrm{ddd}(16.0,11.1,7.2)$ & $33.8 \mathrm{t}$ \\
\hline $2 \mathrm{eq}$ & 2.44 ddd $(16.1,6.6,3.3)$ & & 2.44 ddd $(16.0,6.7,3.7)$ & \\
\hline 3 & & $216.2 \mathrm{~s}$ & & $216.8 \mathrm{~s}$ \\
\hline 4 & & $47.5 \mathrm{~s}$ & & $47.6 \mathrm{~s}$ \\
\hline 5 & & $54.7 \mathrm{~d}$ & & $54.6 \mathrm{~d}$ \\
\hline 6 & & $18.7 \mathrm{t}$ & & $18.8 \mathrm{t}$ \\
\hline 7 & & $30.5 \mathrm{t}$ & & $30.4 \mathrm{t}$ \\
\hline 8 & & $40.6 \mathrm{~s}$ & & $41.4 \mathrm{~s}^{\mathrm{c}}$ \\
\hline 9 & & $50.1 \mathrm{~d}$ & $2.00 \mathrm{br}, \mathrm{s}$ & $52.5 \mathrm{~d}$ \\
\hline 10 & & $36.2 \mathrm{~s}$ & & $36.1 \mathrm{~s}$ \\
\hline 11 & 3.07 br s & $52.5 \mathrm{~d}$ & $5.46 \mathrm{dd}(10.2,3.1)$ & $135.2 \mathrm{~d}$ \\
\hline 12 & 3.07 br s & $57.0 \mathrm{~d}$ & $6.04 \mathrm{dd}(10.2,1.3)$ & $\begin{array}{c}127.4 \\
\mathrm{~d}\end{array}$ \\
\hline 13 & & $87.3 \mathrm{~s}$ & & $89.6 \mathrm{~s}$ \\
\hline 14 & & $41.2 \mathrm{~s}$ & & $41.5 \mathrm{~s}^{\mathrm{c}}$ \\
\hline 15 & & $26.7 \mathrm{t}^{\mathrm{c}}$ & & $25.4 \mathrm{t}$ \\
\hline 16 & & $21.2 \mathrm{t}$ & & $21.2 \mathrm{t}$ \\
\hline 17 & & $43.8 \mathrm{~s}$ & & $44.0 \mathrm{~s}$ \\
\hline 18 & $2.34 \mathrm{dd}(13.6,3.6)$ & $49.6 \mathrm{~d}$ & & $50.5 \mathrm{~d}$ \\
\hline 19 & $1.87 \mathrm{t}(13.5)$ & $37.8 \mathrm{t}$ & $1.81 \mathrm{t}(13.5)$ & $37.3 \mathrm{t}$ \\
\hline 20 & & $31.5 \mathrm{~s}$ & & $31.4 \mathrm{~s}$ \\
\hline 21 & & $34.3 \mathrm{t}$ & & $34.3 \mathrm{t}$ \\
\hline 22 & & $27.0 \mathrm{t}^{\mathrm{c}}$ & & $27.1 \mathrm{t}$ \\
\hline 23 & $1.10 \mathrm{~s}$ & $25.9 \mathrm{q}$ & $1.08 \mathrm{~s}$ & $26.0 \mathrm{q}$ \\
\hline 24 & $1.06 \mathrm{~s}$ & $21.1 \mathrm{q}$ & $1.06 \mathrm{~s}$ & $20.8 \mathrm{q}$ \\
\hline 25 & $1.19 \mathrm{~s}$ & $16.4 \mathrm{q}$ & $1.05 \mathrm{~s}$ & $17.3 \mathrm{q}$ \\
\hline 26 & $1.11 \mathrm{~s}$ & $18.7 \mathrm{q}$ & $1.10 \mathrm{~s}$ & $18.1 \mathrm{q}$ \\
\hline 27 & $1.11 \mathrm{~s}$ & $19.8 \mathrm{q}$ & $1.11 \mathrm{~s}$ & $18.6 \mathrm{q}$ \\
\hline 28 & & $179.2 \mathrm{~s}$ & & $180.0 \mathrm{~s}$ \\
\hline 29 & $1.00 \mathrm{~s}$ & $33.2 \mathrm{q}$ & $0.98 \mathrm{~s}$ & $33.3 \mathrm{q}$ \\
\hline 30 & $0.93 \mathrm{~s}$ & $23.6 \mathrm{q}$ & $0.89 \mathrm{~s}$ & $23.5 \mathrm{q}$ \\
\hline
\end{tabular}

a $\delta$ in ppm and $J$ (in parentheses) in Hz.

${ }^{\mathrm{b}}$ Assignments were based on ${ }^{1} \mathrm{H}-{ }^{1} \mathrm{H}$ COSY and HETCOR experiments and comparison with spectroscopy data reported in the literature (Ikuta and Morikawa, 1992; Pereda-Miranda and Delgado, 1990; Seo et al., 1975).

c Assignments could be reversed. Chemical shifts were determined at $500\left({ }^{1} \mathrm{H}\right)$ and $75\left({ }^{13} \mathrm{C}\right) \mathrm{MHz}$. Carbon multiplicities were determined by DEPT experiments.

\section{Plant material}

Fruits and seeds from Cedrela montana were collected along the road to Puente de Piedra (Cundinamarca, Colombia) in December 1994. The plant was identified by M. Sc. Maria E. Morales. Voucher specimen has been deposited at the Herbario Nacional Colombiano. Universidad Nacional de Colombia. No. 289.532

\section{Extraction and isolation}

Dried fruits and seeds $(2.65 \mathrm{~kg})$ were extracted successively with petroleum ether (b.p. $40-60^{\circ}$ )
(10 l) and $\mathrm{CH}_{2} \mathrm{Cl}_{2}$ (7 l). After evaporation of solvents, green syrups A (35 g) and B (28 g) were obtained respectively.

The petroleum ether (b.p. $40-60^{\circ}$ ) extract A (33.5 g dry wt.) was chromatographed on a silica gel column $(600 \mathrm{~g})$ eluting with petroleum ether and mixtures of $\mathrm{CH}_{2} \mathrm{Cl}_{2}-\mathrm{MeOH}(8: 2 \mathrm{v} / \mathrm{v}) .120$ fractions of $500 \mathrm{ml}$ each were collected and pooled according to their TLC patterns to give several major fractions. Fractions 50-55, after crystallization from $\mathrm{MeOH}$, yielded a mixture of $\beta$-sitosterol and stigmasterol (m.p. $134-136^{\circ} \mathrm{C}$ ). Fractions $75-91(650 \mathrm{mg})$ were purified by preparative TLC 
and eluted with petroleum ether $-\mathrm{CH}_{2} \mathrm{Cl}_{2}(7: 3 \mathrm{v} / \mathrm{v})$ to give after crystallization from $\mathrm{CH}_{2} \mathrm{Cl}_{2}-\mathrm{MeOH}$, oleanonic acid (3) (450 mg) as white crystals (m.p. $\left.183{ }^{\circ} \mathrm{C}\right)$ (Campos et al., 1991)

The $\mathrm{CH}_{2} \mathrm{Cl}_{2}$ extract $\mathrm{B}$ ( $27 \mathrm{~g}$ dry wt) was subjected to flash chromatography on silica gel (486 g) and eluted with petroleum ether, $\mathrm{CH}_{2} \mathrm{Cl}_{2}$ and $\mathrm{MeOH}$. 171 fractions of $500 \mathrm{ml}$ each were collected and pooled according to their TLC patterns to give several major fractions. Fractions 50-60 purified by preparative TLC afforded $300 \mathrm{mg}$ of a mixture of $\beta$-sitosterol and stigmasterol. Fractions 79-83 were separated by preparative TLC using petroleum ether $-\mathrm{CH}_{2} \mathrm{Cl}_{2}(7: 3 \mathrm{v} / \mathrm{v})$ giving $100 \mathrm{mg}$

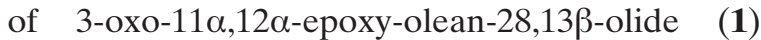
and $4 \mathrm{mg}$ of 3-oxo-olean-11-en-28,13 $\beta$-olide (2). Fractions 98-108 (1.8 g) were rechromatographed on a silica gel column (40 g), eluted with petroleum ether and mixtures of $\mathrm{CH}_{2} \mathrm{Cl}_{2}-\mathrm{MeOH}$ giving $15 \mathrm{mg}$. of photogedunin (4) (Céspedes et al., 1998) as a white solid (m.p. $286^{\circ} \mathrm{C}$ ).

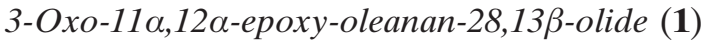

M.p. $281{ }^{\circ} \mathrm{C}\left(\mathrm{CH}_{2} \mathrm{Cl}_{2}-\mathrm{MeOH}\right), \mathrm{IR}_{\mathrm{KBr}}\left(\mathrm{cm}^{-1}\right)$ : 2945, 2860, 1770, 1708, 1477, 1449, 1392, 1139, 873.

Ahmad V. U. and Atta-ur-Rahman A. V. (1994), Handbook of Natural Products Data: Pentacyclic Triterpenoids. Vol. 2 Elsevier, Amsterdam-London-New York. pp. $1-512$.

Banerji B. and Nigam S. K. (1984), Wood constituents of Meliaceae: A review. Fitoterapia, LV, 3-36.

Barton D. H. R. and Holness N. J. ( 1952 ), Triterpenoids. Part V. Some relative configurations in rings C, D, and $\mathrm{E}$ of $\beta$-amyrin and the lupeol group of triterpenoids. J. Chem. Soc. 78-92.

Campos A. M., Oliveira F. S., Iracema M., Machado L., Braz-filho R. and Matos F. J. A. (1991), Triterpenes from Cedrela odorata. Phytochemistry 30, 1225-1229.

Céspedes C. L., Calderón J. S., King-Díaz B. and LotinaHennsen B. (1998), Phytochemical and biochemical characterization of epimeric photogedunin derivatives. Their different sites of interaction on redox electron transport carrier of Spinacea oleracea L. chloroplasts. J. Agric. Food Chem. 46, 2810-2816

Champagne D. E., Koul O., Isman M. B., Seudder G. G. E. and Towers G. H. N. (1992), Biological activity of limonoids from the Rutales. Phytochemistry 31, 377-394.

Hui W. and Li M. (1976). Two new triterpenoids from Rhodomyrtus tomentosa . Phytochemistry 15, 17411743.

Ikuta A. and Morikawa. A. (1992), Triterpenes from Stauntonia hexaphylla callus tissues. J.
EIMS (probe) $70 \mathrm{eV} \mathrm{m/z} \mathrm{(rel.} \mathrm{int.):} 468[\mathrm{M}]^{+}$(50), 453 (26), 450 (15), 440 (10), 424 (5), 422 (20), 407 (15), 368 (12), 263 (50), 248 (20), 233 (100), 204 (65), 189 (75).

\section{3-Oxo-olean-11,12-en-28,13 $\beta$-olide (2)}

Gummy solid. $\operatorname{IR}_{\mathrm{KBr}}\left(\mathrm{cm}^{-1}\right):$ 2940, 2850, 1765, 1705, 1640, 1610, 1470, 1390, 1035, EIMS (probe) $70 \mathrm{eV} \mathrm{m} / z$ (rel. int.): $452[\mathrm{M}]^{+}(100), 408$ (80), 255 (18), 201 (12), 203 (10), 193 (50), 189 (59), 187 (30).

\section{Acknowledgements}

Authors wish to thank Pablo Leyva, and Dr. Nivea Cristina Garzón, from the Instituto de Ciencias Naturales, Universidad Nacional de Colombia. Also to Dr. Fabiola Espejo from Instituto Nacional de Inmunología de Colombia, and Luis Velasco, Rocío Patiño and M. Sc. Isabel Chávez from Instituto de Química, Universidad Nacional Autónoma de México, for recording the EIMS, IR, ${ }^{1} \mathrm{H}$ NMR and ${ }^{13} \mathrm{C}$ NMR spectra.

Nat. Prod. 55, 1230-1233.

Iwamoto M., Okabe H. and Yamauchi T. (1985) Studies on the constituents of Momordica cochinchinensis Spreng. II. Isolation and characterization of the root saponins, Momordins I, II and III. Chem. Pharm. Bull. 33, $1-7$.

Kitagawa I., Kitazawa K. and Yosioka I. (1968), Photooxidation of oleanolic acid: Formation of $11 \alpha, 12 \alpha$-epoxy- and $12 \alpha$-hydroxy-oleanolic lactones. Tetrahedron Lett. 509-512.

Kitagawa I., Kitazawa K. and Yosioka I. (1972), Photochemical transformation leading to eupteleogenin-I. Introduction of epoxy-lactone system. Tetrahedron 28, 907-921.

Majumder P. L. and Bagchi A.(1983), Oxidative transformations of triterpenoids of the ursane and oleanane skeleta with hydrogen peroxide. Introduction of 11,12 -double bond and $13(28)$ oxide moiety in the ursane system. Tetrahedron 39, 649-655.

Pereda-Miranda R. and Delgado G. (1990), Triterpenoids and flavonoids from Hyptis albida. J. Nat. Prod. 53,182-185.

Seo S.,Tomita Y. and Tori K. (1975) Carbon-13 NMR spectra of urs-12-enes and application to structural assignments of components of Isodon japonicus $\mathrm{H}$. tissue cultures. Tetrahedron Lett. 7-10. 